\title{
The Influence of Positive Behavioural Changes on HIV/AIDS Prevalence amongst Adolescents and Youths in Niger State, Nigeria
}

\author{
Article by Otojareri Kohwo Anthony \\ NHIS Unit, Federal Medical Centre, Nigeria \\ E-mail: otojareri.kohwo@yahoo.com
}

\begin{abstract}
Human Immunodeficiency Virus (HIV) which causes the disease, Acquired Immunodeficiency Diseases Syndrome, is a public health challenge that is yet to have a cure and still contributes to the global disease burden.

This descriptive study was carried out to examine the effect of positive behavioural factors on the prevalence of HIV/AIDs amongst adolescent and youths attending the antiretroviral clinics of four general hospitals in Niger State, Nigeria. These were the general hospitals in Bida, Minna, Suleja and Kontagora. A total of 268 participants took part in the study in which a multistage (2-stage) random sampling technique was used (Bamise, Bamise and Adedigba, 2011). First stage involved the random selection of the four general hospitals used for the study whilst the second stage involved the random selection of participants at the various general hospitals selected for the study.

In order to participate in the study, the participants must be within the age bracket of adolescent and youths and must be retroviral positive. The instrument for data collection was a pretested semistructured questionnaire. Data analysis was carried out using both descriptive and inferential statistics.

Results: A total of 268 respondents were interviewed. More male participated in the study and majority of the participants were concentrated within the age bracket $(21-25)$ years. The awareness of the participants about HIV/AIDs is high with 98.2 percent participants believed that condom use prevented HIV/AIDs. About 66 percent of respondents had only one sexual partner, 56.3 percent used condom and other preventive method as a form of positive life style change in behaviour whilst 51.1 percent of respondents practiced abstinence from sexual intercourse.

Conclusion: The study showed there was high level of awareness about HIV/AIDs and positive life style behaviour was found to have effect on prevalence of HIV/AIDs among the target group for the study.

From the finding, more awareness programs about HIV/AIDs should be carried out among adolescent and youths. Government and Nongovernmental organization should partner with the community, faith based organization, schools to implement these findings.
\end{abstract}

Keywords: Human Immunodeficiency Virus, Adolescent, Youths, lifestyle changes.

\section{Introduction}

Human Immunodeficiency Virus (HIV) continues to be a major public health challenge that is yet to have a cure, and still contributes immensely to the global disease burden.

The epidemic amongst adolescents is fast growing because of young people/adolescents vulnerability to becoming infected with the disease. Students in secondary schools who are commonly adolescents as well as young people who are at an age when sexual activity is just beginning or had already begun are potentially at risk of contracting HIV, unless they are properly informed to see themselves at risk and undertake safer sexual practices.

Adolescence is defined as the age from 10-19 years and young adult 15-24years (UNICEF, 2013) as a period many begin to explore their sexuality and so be able to have access to sexual and reproductive health information to guide him or her. Their limitation of access to this information because of their age, socio-economic status and beliefs, have led to the need for protection against HIV infection which perhaps is being underplayed by the family and society.

There have been various global declarations and commitments from world leaders setting specific goals and targets to respond to HIV/AIDs epidemic since the year 2000. The United Nations General Special Assembly (UNGSA) on HIV/AIDs in 2001, specifically set a target to reduce prevalence of HIV in young people aged $15-24$ years globally by 25 percent by end of 2010 and to increase young 
Texila International Journal of Public Health

Volume 5, Issue 3, Sep 2017

people's access to essential HIV prevention information skills and services so as to reach 95 percent of those in need by 2010 (UN, 2001). Young people are especially vulnerable to HIV infection because of the physical, psychological, social and economic attributes of the adolescence (Earl, 1995;Oppong and Oti-Boadi, 2012). Early and risky sexual activity increase adolescents and young people's vulnerability to HIV (UNAIDS 2007).

Youths are a very potential population subset that must be understood, and so it is necessary that studies be carried out which will focus on promoting desired positive behaviour change among the adolescent age cohort, because of the physiological changes that drives them to engage in risky behaviour that could make them contract HIV. Such studies may provide guidelines on how to promote desired behaviour change among youths/adolescents to prevent them from contracting HIV/AIDS, especially now that no known and effective cure has been found for.

Many teenagers engaged in sexual intercourse without proper protection and awareness about HIV/AIDs and STI's (Srivastava and Srisvastara, 2011). It has been observed that most youths become sexually active before marriage whilst still in their teens. Most adolescents and especially secondary school students in Nigeria are potentially at risk of contracting HIV through unprotected sexual intercourse (Musa et al., 2008).

Studies showed that about 50\% of unmarried teenagers, aged $15-19$ years had begun sexual activity without proper protection (Musa et al., 2008). There are many religious and cultural ways which had helped to change sexual behaviors positively and which had helped to eliminate further spread of HIV. Moreover unprotected sexual contact is still the most frequent means of prevention of transmission of HIV.

HIV prevention behaviour programs are targeted at individuals, families, communities and entire societies. Such well-designed programs promote individual knowledge and perception of risk and increase individual motivation to avoid risky behaviour. Also, results of the study showed that having an awareness of HIV/AIDS did not appear to improve misconceptions or translate into personal actions and precaution to avoid contracting the HIV/AIDs virus. Most of the knowledge about HIV/AIDs were obtained from sources as television, radio and schools. In a similar study on HIV/AIDS and sexual risk behaviour among adolescents: Factors influencing use of condoms in Burkina Faso, Georges and Nyovanic (2007), noted that programs designed to improve knowledge and awareness about HIV were usually based on the premise that greater knowledge among adolescents will lead to positive changes in their sexual behaviour. However, earlier researchers observed a lack of association between HIV knowledge and sexual behaviour (Akwena, Madise and Hindle, 2003).

Omoyemi, Akiyemi and Fatusi (2012), pointed out that about $75 \%$ of sexually active adolescents had high knowledge of HIV/AIDS. The authors further reported that regardless of adolescent level of HIV knowledge, those with higher education, older age at first sex, higher wealth index and from urban location are less likely to engage in HIV non protective sexual behaviour compared to adolescents.

John, Okolo and Isichci (2014), observed that early sex, multiple sexual partners and unprotected sex, forced sex and female genital mutilation are among factors associated with increased transmission of HIV/AIDs among adolescents.

In another study, Abasiubong, Udoh, Idung and Umoiyohs (2012), noted that life style affected the prevalence of HIV/AIDs amongst adolescents, and suggested that lifestyle modification should be given adequate attention. They also found that there was higher sexual activity amongst women than men and unhealthy attitudes and sexual behaviour among individuals living with HIV/AIDs. The authors encouraged the need to initiate concrete policies and programs that would encourage people living with HIV/AIDs to adopt a healthy lifestyle. The authors however, did not explain further what was meant by unhealthy attitudes.

Ndegwa, Wanderi and Mwisuka (2012), noted that positive behaviour change has been fronted as the most likely scientific basis for the reduction of HIV prevalence, as the spread of AIDs virus is mainly through sexual behaviour.

Findings from a study carried out by George and Janet (2007), on condom use in Burkina Faso, showed that overall use of condom was low and inconsistent among adolescents, recommending that young people's awareness needs be improved by promoting condom use in other to reduce HIV/AIDS prevalence. 
About 3.2million people are living with HIV in Nigeria, with an adolescent and youth HIV prevalence as 4.1 percent as at 2010(NACA). About 220,000 new cases of HIV infection has been reported whilst AIDs related death account for 210,000 people (UNAIDS, 2014).

Of the number of people living with HIV globally, 9 percent of them reside in Nigeria (UNAIDS, 2014). This figure is small when compared to figures from other sub-Saharan countries such as Zambia $12.5 \%$ and South Africa 19.1\% (UNAIDS 2014).Nigeria together with South Africa and Uganda, account for almost half of all annual new HIV infections in sub-Saharan Africa. This is despite achieving a 3.5 percent reduction in cases of new infection between 2005 and 2013 (UNAIDS, 2014

Also, studies on adolescents sexual behaviors carried out in other West African countries have shown that a range of factors including lack of reproductive health and HIV/AIDs information and services contributed to heightened risk of HIV among young people. Biglanet al., 1990, Santelliet al., 2000.

Several of these publications on social and behavioural factors associated with high risk sexual behaviour among adolescents coupled with very few functioning programmes on prevention of HIV/AIDs on adolescent and youth which will help in curbing the rising prevalence of HIV/AIDs are in place and not functional in this part of the country hence the need to carry out this study on the effect of positive behavioural changes on prevalence of HIV/AIDs amongst Adolescents and Youth in Niger Stat

\section{Methodology}

The study was carried out in four general hospitals, which are located in Bida, Minna, Kontagora and Suleija in Niger state of Nigeria. A descriptive study design was used to determine the effect of positive behavioural factors on prevalence of HIV/AIDs among adolescence and youths in Niger state of Nigeria.

Minimum sample size of 268 was obtained using the formula

$$
\mathrm{N}=\frac{\mathrm{Z}^{2} \mathrm{pq}}{\mathrm{d}^{2}}(\text { Araoye, 2014) }
$$

Where:

$\mathrm{N}=$ Desired Sample size

$\mathrm{Z}=$ Standard normal deviate usually set at 1.96

$\mathrm{P}=$ the proportion in the target population estimated to have a particular characteristic

$\mathrm{Q}=1.0-\mathrm{p}$

$\mathrm{d}=$ Degree of accuracy desired usually set at 0.05

A survey carried out by the Nigeria National reproductive health reports that only about $18.3 \%$ of adolescents/youths have complete knowledge of HIV/AIDs infection (FMOH, 2003). P which is the proportion in the target population with a particular characteristic is therefore $18.3 \%$

Therefore

$$
\begin{aligned}
& \mathrm{Z}=1.96 \\
& \mathrm{P}=0.183 \\
& \mathrm{Q}=1-0.046=0.954 \\
& \mathrm{D}=0.05 \\
& \mathrm{n}=\frac{\mathrm{Z}^{2} \mathrm{pq}}{\mathrm{d}^{2}}=\frac{(1.96)^{2} \times 0.183 \times 0.954}{(0.05)^{2}} \\
& \mathrm{n}=268
\end{aligned}
$$

If is $n=268$, therefore minimal sample size $=268$

A multistage (2-stage) sampling technique in which first stage random sampling was used to select the four general hospitals where the study was to be carried out, whilst second stage involved the random selection of the 268 participants for the study with inclusive criteria as each participant being within the age bracket of adolescent and youth and must be retroviral positive. A pretested questionnaire was used for the study. Data were collected suing structured questionnaires. 
Texila International Journal of Public Health

Volume 5, Issue 3, Sep 2017

Questionnaires were checked for completion of filled questionnaire and mistakes and subsequently sorted out. Descriptive and inferential statistics were carried out to analyses the data.

Ethical approval was sought and obtained at the Niger State Health Management Ethical Committee to carry out the study in the four general hospitals.

\section{Results}

\section{Demography}

The demographic data analyzed included the respondents Sex, Age, Marital Status, Educational Background and Occupation. The results are shown below in the tables

Table 1. Demography

\begin{tabular}{|l|l|l|}
\hline VARIABLE & $\begin{array}{l}\text { FREQUENCY } \\
\text { (N=268) }\end{array}$ & PERCENT \\
\hline GENDER & 146 & \\
Male & 122 & 54.5 \\
Female & & 45.5 \\
AGE GROUP & 30 & \\
$11-15$ years & 80 & 11.2 \\
$16-20$ years & 158 & 29.9 \\
$21-25$ years & & 58.9 \\
MARITAL STATUS & 137 & \\
Married & 120 & 51.1 \\
Single & 10 & 44.8 \\
Widow & 1 & 3.7 \\
Widower & & 0.4 \\
EDUCATIONAL & & \\
QUALIFICATION & 20 & 7.5 \\
Primary School & 109 & 40.7 \\
Secondary School & 135 & 50.4 \\
Tertiary Institution & 04 & 1.5 \\
Not schooled & & \\
OCCUPATION & 112 & 41.8 \\
Employed & 112 & 41.8 \\
Unemployed & 44 & 16.4 \\
Student &
\end{tabular}

More males (54.5) participated in the study and majority of the participant in the study fall with age group $21-25$ years. A higher proportion of the participant $51.1 \%$ were married, while majority 50.4 attended tertiary institution.

Table 2. Knowledge of HIV/AIDS

\begin{tabular}{|l|l|l|}
\hline VARIABLE & FREQUENCY (N=268) & PERCENT \\
\hline HEARD ABOUT HIV/AIDS & 256 & \\
Yes & 12 & 95.5 \\
No & & 4.5 \\
USE OF CONDOM & & \\
PREVENTS HIV/AIDS & & \\
& 239 & 89.2 \\
Yes & 20 & 7.5 \\
No & 09 & 3.4 \\
Don't know & & \\
\hline
\end{tabular}

Majority of participants $95.5 \%$ had heard about HIV/AIDs, while $89.2 \%$ participants believed use of condom prevented HIV/AIDs 
Table 3. Lifestyle and sexual behaviour

\begin{tabular}{|l|l|l|}
\hline VARIABLE & FREQUENCY (N=268) & PERCENT \\
\hline HAD SEX BEFORE & & \\
Yes & 222 & 82.8 \\
No & 46 & 17.2 \\
NUMBER OF SEXUAL & & \\
PARTNERS & 177 & 66.0 \\
One & 40 & 14.9 \\
Two & 08 & 3.0 \\
More than Two & 43 & 16.0 \\
None & & \\
USE OF CONDOM OR & & \\
OTHER PREVENTIVE & 151 & 56.3 \\
METHOD & 117 & 43.7 \\
Yes & & \\
No & 131 & 48.9 \\
ABSTINENCE FROM SEX & 137 & 51.1 \\
Yes & & \\
No & & \\
\hline
\end{tabular}

Majority of participants $82.8 \%$ had sex before (sexually active), while $66 \%$ of participants had only one sexual partner, and majority $56.3 \%$ used condom to prevent HIV/AIDs. A higher proportion $51.1 \%$ did not abstain from sex.

\section{Discussion}

Findings from the study showed more males participated in the study as shown. This could be as a result of the explorative nature of the male adolescent and youth.

A larger proportion of the respondents were within the age bracket ( $21-25$ years). This result is similar to a study by (lwelamira et al., 2012) which reported that most of the new HIV/AIDs infections were heavily concentrated among the young aged (15-24 years). Youths were said to have accounted for more than 60 percent of people living with HIV/AIDs (Joint United Nations program on HIV/AIDs, 2006, Okouta, 2007; Bankola et al., 2007; Lwelamira et al., 2012).

A higher proportion 137 (51.1 percent) of the total number of respondents were married. This was attributed to cultural practice of early marriage in the area where the study was carried out.

Majority of the respondents ( 98.5 percent) were literate as they had one form of education or the other. This suggests a tremendous improvement in the literacy level in Niger State, Nigeria.

However, it is not surprised that less than half of the total number of respondents ( 41.8 percent) are employed, especially in the face of a level of unemployment rate in Nigeria.

On Awareness of HIV/AIDs, the study revealed respondents' knowledge about HIV/AIDs was very high, with 95.5 percent of total respondent having heard about HIV/AIDs. This finding support the study carried out by Wodi (2005) on knowledge, attitude and opinion about HIV/AIDs among adolescents, in which 93 percent of respondents in that study had heard about HIV/AIDs. Another study by Omoyeni, AKiyemi and Fatusi (2012) which supported this study found out that about 75 percent of sexually active adolescent had high knowledge of HIV/AIDs.

Knowledge of preventive methods from the study revealed 89.2 percent of total respondents believed use of condom prevented HIV/AIDs, as shown below. This is in contrast to another study carried out by Srivastava and Srisvastara, (2011) in which it was reported many teenagers engaged in sexual intercourse without proper protection and awareness about HIV/AIDs and sexually transmitted infections (STI's). This also corroborates the known fact internationally that adolescent sexual activity is characterized by a low incidence of condom use (Legue, et al., 1986; Bandawa and Foster, 1996, Maluwa - Band, 1999, 2010).

On life style and sexual behaviour, 82.8 percent of total respondent consented to having had sex before and that pointed to the fact that the remaining respondents who were obviously HIV positive must have contracted HIV/AIDs through another means apart from sex.

Majority of respondents (66.0 percent) had only one sexual partner. This finding contrast the known international fact that adolescent sexual activity is characterized by early onset of sexual 
Texila International Journal of Public Health

Volume 5, Issue 3, Sep 2017

activity, multiple sexual partners and low incidence of condom use (Iegue et al., 1986). Also findings from the study showed 56.3 percent of total respondents made use of condom or other preventive method as a form of positive lifestyle change in behaviour, with a large number of respondents (43.7 percent) being exposed to contracting HIV/AIDs through unprotected sex.

The study also showed that 51.1 percent of total respondents practiced abstinence from sex which goes to prove that a large proportion of respondents did not practice abstinence from sex which is a major positive lifestyle/behaviour change that affects the spread/ prevalence of HIV/AIDs.

\section{Conclusion}

The study set out to examine the influence of positive behavioural change on the prevalence of HIV/AIDs among adolescents/youths in Niger State.

From the results in the study, it was found out that:

Positive lifestyle behaviour change had effect on prevalence of HIV/AIDs.

Prior knowledge of HIV/AIDs did not have an influence on the prevalence of HIV/AIDs amongst adolescents/youths in Niger State.

That there was association between occupation and being infected with HIV/AIDs amongst adolescents and youths in Niger State.

The risk of contracting HIV/AIDs is high with increased number of sexual partners.

There was a high level of awareness about HIV/AIDs disease amongst adolescents and youths in Niger State and positive lifestyle behaviour change had effect on prevalence of HIV/AIDs amongst adolescent and youths in Niger State.

\section{Recommendation}

A directorate of adolescents and youths be created with certain position reserved for the adolescent and youths to help to help in planning of programs initiated and implemented for them. There should be a revised curriculum for the schools which must include course on sex education, to be taught to all students.

Government must improve partnership with various communities, organizations as a way of improving adolescent and youth's knowledge on HIV/AID.

There should be a directorate of adolescents and youths created, with certain positions reserved for the adolescents and youths to help them be part of all programs initiated and implemented for them.

There should be a revised curriculum for the schools which must include courses on sex education, to be taught to all students. Various non-governmental agencies specialized in adolescents and reproductive health should be set up to partner with government, religious bodies, private schools etc.

Government must improve partnership with various communities, organizations as a way of improving adolescents and youth's knowledge on HIV/AIDs.

\section{Limitation}

This study would have been carried out using all available antiretroviral center from primary healthcare centre to large hospitals. However, the limiting factor were large geographic spread of the health facilities within Niger State, poor funding and insufficient time frame for the study.

\section{References}

[1]. Abasiubong F, Udoh, SB, Idung, AU, Umoiyoho, AJ (2012) Attitudes and sexual behaviour of unmarried people with HIV/AIDS living in the Niger Delta region of Nigeria. Mental Health Fam Med V 9 (4): 225 - 232.

[2]. Adedigba, Bamise, 2011. Knowledge of HIV/AIDs among Secondary School Adolescent in Osun State, Nigeria. Nigeria Journal of Clinical Practice Vol. 14(3): 338 - 344.

[3]. Akwena PA, Madise NJ, Hinde A, (2003) A perception of risk of HIV/AIDs and sexual behaviour in Kenya. Journal of Biosocial Science. 35 (3): 385 - 411.

[4]. Araoye M.O, (2004). Subject selection. In Research Methodology with statistics for health and social science $1^{\text {st }}$ ed. Ilorin, Nathadex: 117-8.

[5]. Bankole A. A, Briddlecom G, Guiella, S. Suigh and Zulu E 2007.Sexual behaviour, knowledge and information sources of very young adolescents in four sub-Saharan African countries. African J. Reproductive Health, 11(3): 28

[6]. Fatasi A. O (2005) Adolescent sexual and reproductive health needs in Nigeria: shaping a pragmatic and effective response. Journal of community medicine and primary Healthcare.17:1 -6. 
[7]. Georges G, Nyoran J, M (2007) HIV/AIDs and sexual - risk Behaviour among Adolescent: Factors influencing the use of condoms in Burkina Faso. Afr. Afr. J. Report Health 11(33): $182-196$.

[8]. John C, Okolo SN, Isichei C (2014) Sexual risk behaviour and HIV infection among adolescent in secondary schools in Jos, Nigeria. Niger J Paed. 41(2): $86-89$.

[9]. Joint United Nations Global Fact Sheet, 2015.

[10]. Logoe, W.L. Klepp, K. I and Skutle, A (1996) Sexual debut and predictors of condom use among secondary school students in Arusha, Tanzania, AIDS care, 8 (4), 443 - 452.

[11]. Lwelamira J, Sarwatt A and Masumbuko J, 2012. Knowledge and practices related to HIV/AIDS infection among youth in Minning areas of Central Tanzania: A case of London and Winza Minning Area. Asian Journal of Medical Science 4(4): 134 - 144.

[12]. Maluwa - Banda DW 2010. HIV/AIDS Related Knowledge and self-Reported sexual behaviour of secondary school students in Southern Malawi: Implication of AIDS Education and counseling. Available at http://www.apicom.org/ids - document Retrieved October 17, 2013 4:00pm.

[13]. Musa O I, Akande TM, Salaudeen AG, Soladoye OM, 2008. Family Communication on HIV/AIDS among secondary school students in a Northern State of Nigeria. Afr. J. Infect Dis 2 (1): 00 - 00.

[14]. Ndegwa, I, N, Wanderi, M, P. Nwisukha A (2012), Factors Influencing behaviour change for the prevention of the spread of HIV/AIDS among students in Gitthunguri Division, Gitthunguri District, Kenya. International Journal of Business and Social Sciences. 3(16)

[15]. Nigerian National Agency for the control of AIDs 2010a and Nigeria National Agency for the control of AIDs, 2010b.

[16]. Nigeria National Agency for the control of AIDs, 2010a.National HIV/AIDs strategic plan 2010 - 2015. Nigerian National Agency for the control of AIDs, Abuja, Nigeria http://Nigeria.unfpa.org/pdf/nsp.pdf (accessed 9 February, 2013).

[17]. Omoyeni S T, Akinyemi A. I, Fatusi A, (2012). Adolescents and HIV related behaviour in Nigeria: Dee's knowledge of HIV/AIDs promote protective sexual behaviour among sexually active Adolescents? Paper presentation at the 2012 population Assocation of American Annual Meeting Program. San Francisco California.

[18]. Okonta P. 1, 2007 Adolescent Sexual and reproductive Health in the Niger Delta region of Nigeria Issues and Challenges. Afr. J. Reprod. Health, 11(11): 113 - 124.

[19]. Santelli JS IndbergLd, Abma J, McNeely CS, Resurek M, (2002) Adolescent Sexual behaviour, Estimates and trends from four nationally representation surveys family planning perspectives. 32(n4); $156-194$ (Pub.Med).

[20]. Srivastava B and Srivastava A, 2011, a study on open discussion of HIV/AIDs among secondary school students with their parents in national capital regions (NCR) of India. Elixir Soc. Sci. 41, 6029- 603.

[21]. UNAIDS (2014) The 'Gap Report'.

[22]. United Nations (2001) Declaration of Commitment on HIV/AIDS, United Nations General Assembly Special Session on HIV/AIDS.25, New York.

[23]. Wodi B. E (2005) HIV/AIDs Knowledge Attitude, and Opinions among Adolescents in the River State of Nigeria. The International Electronic Journal of Health Education. 8; 86 - 94 http://www.jejhe.org 